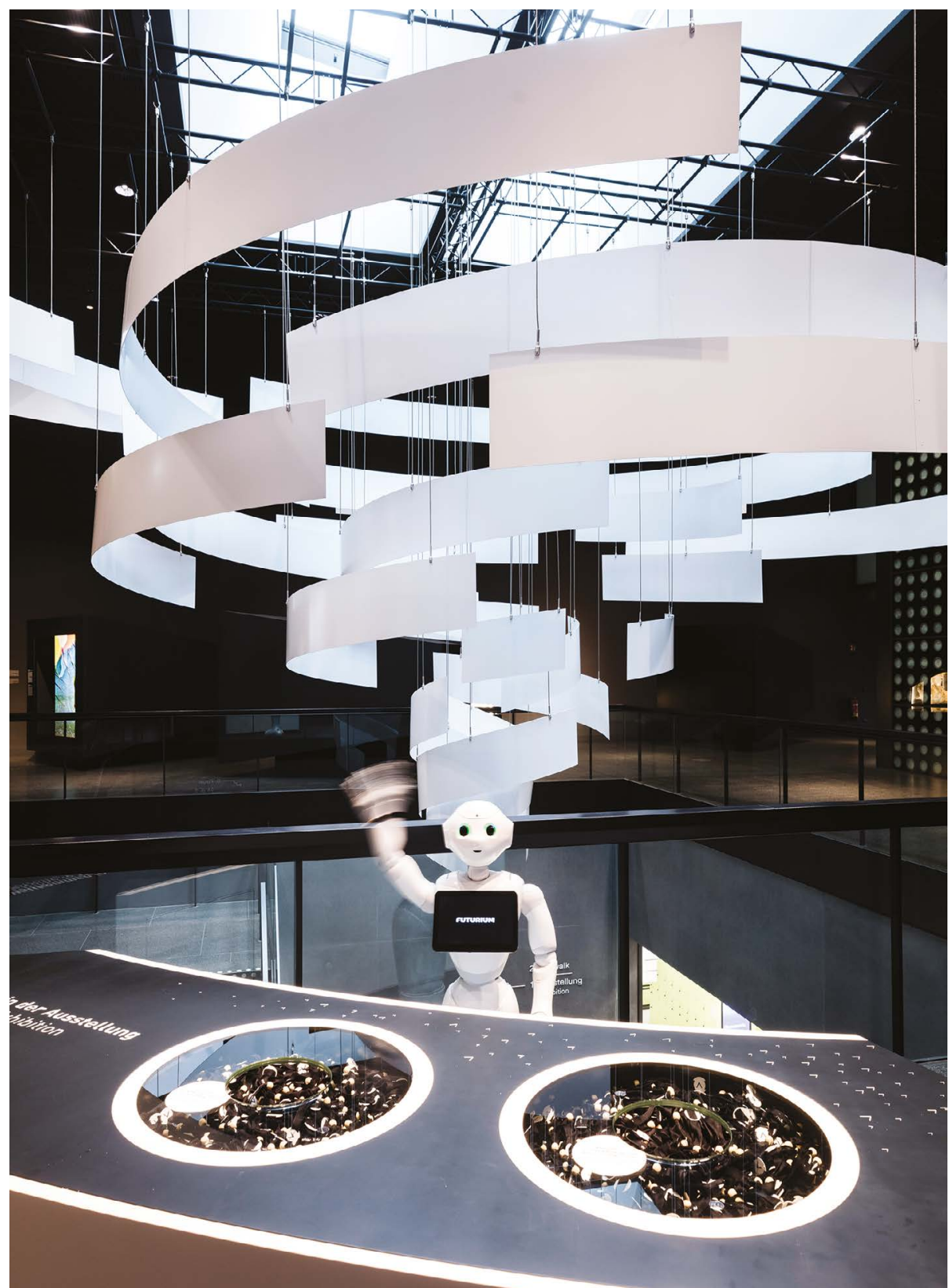

Pepper the robot greets visitors to Berlin's Futurium.

\section{Lost in the house of tomorrow}

\section{What kind of future does Berlin's newest museum really show us? By Stephen Cave}

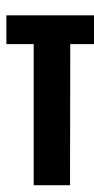
hirty years ago, the future became passé. When the Berlin Wall fell in late 1989 and the communist regimes that hid behind it collapsed, political scientist Francis Fukuyama called the event "the end of history". But he also cast it as the finale of the future: the end of imagining how things might be different. The utopian visions driving both communism and fascism had been discredited and defeated. They were to be replaced by an eternal 'now' that, in Fukuyama's words, saw “Western liberal democracy as the final form of human government".

In the intervening decades, past and future have been reasserting themselves. Throwbacks such as right-wing populism are challenging liberal complacency, and environmental apocalypse is emerging as the face of the future. But most people in high-income countries would rather avert their eyes to focus on a still-comfortable consumerist present. At such a time, imagining a positive future is a challenge, but a new initiative in Berlin wants to try.

The Futurium, billed as a "house of futures", is a museum, exhibition space and site for education and conferences. The $€ 58$-million (US\$64-million) building, designed by Berlin architects Richter Musikowski, shimmers in asymmetrical glass and metal, like a 1960s vision of the space age squashed between office blocks on the banks of the River Spree. It opened in September in the presence of Anja Karliczek, head of Germany's Federal Ministry for Education and Research, the museum's largest funder. Other backers include leading scientific institutes such as the Fraunhofer Society, Helmholtz Association and Max Planck Society.

How do these prestigious bodies invite us to imagine the future? Oddly timidly, in my view - with a focus on new technologies and modest hints for living sustainably. The opening exhibition reveals deeper issues with the thinking behind the space.

The Futurium's three floors are divided into a basement 'lab' for workshops, a ground-floor 'forum' for larger events and an exhibition space above. The last is divided into three 'thinking spaces': Human, Nature and Technology, each with its own exhibition - respectively, Common Cause, Rethinking Nature and Towards New Horizons. A humanoid robot ('Pepper', made by SoftBank Robotics in Paris) acts as greeter, dispensing wristbands that contain implanted radio-frequency identification chips. At various points in the show, visitors can vote for a possible future by pressing 


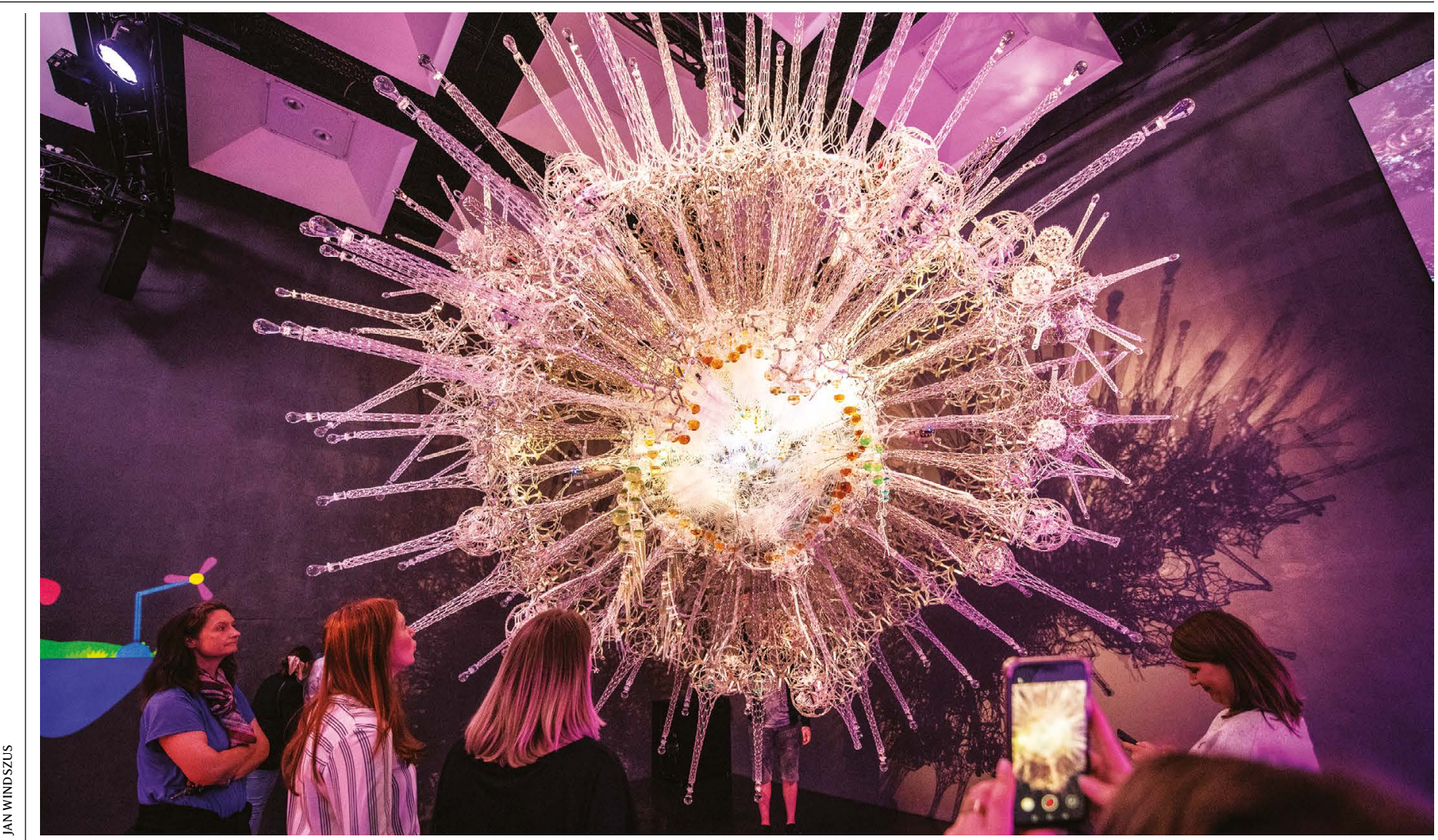

Philip Beesley's cell-simulating 2018 sculpture Noosphere on display at the Futurium.

their wristband against a scanner. For example, they can choose whether they would prefer to live on after death as a digital avatar, pass their data to their loved ones or have all electronic traces of themselves deleted.

Past Pepper, the layout is baffling, with little indication of what is where, or why. When I stumbled across the Technology thinking space, however, I found the exhibits informative, with concepts such as big data and artificial intelligence explained well. Visitors of all ages are kept engaged by various gadgets, such as tablet computers that provide an augmented view of some displays.

\section{Connected realms}

The Human space invites us to consider topics such as the networked society and future cities. A central focus is overconsumption, with a rather messy series of exhibits prompting visitors to consider how much stuff they really need, and promoting the benefits of decluttering. In the Nature area, themes include urban farming and renewable energy. An exhibit on sustainable biomaterials presents some provocative alternatives to plastics - shoes made from algae, and fungus-based furniture. The curators intend to update the whole exhibition gradually, and to introduce major new themes annually from 2021. These individual elements are stimulating.

But I found the conceptual basis for the Futurium's structure - the division into human, technology and nature - problematic. An installation at the start of the exhibition displays the three concepts as linked but

\section{"To portray technology as unconnected to humans fuels technological determinism."}

distinct, with 'technology' far removed from 'people', and 'natural' nodes such as ecosystems or even the laws of nature on a par with art and faith. These separations are deeply misleading. To portray technology as unconnected to humans fuels technological determinism; to portray it as separate from nature is to perpetuate the Western myth that technology exists to dominate an unruly Earth.

Prising the human away from nature is perhaps the most egregious of all; it implies that we are self-contained, rather than dependent on a biosphere increasingly under threat. Other framings, such as humanity as a subset of nature, and technology as a subset of the human, might have been better suited to the messages about sustainability that the museum ultimately wants to promote.

Overall, the Futurium succeeds best as a showcase for the shiniest aspects of the present. In this way, it resembles other tech-engagement centres, such as Science Gallery Dublin and its six sister venues around the world, or Tokyo's National Museum of Emerging Science and Innovation. But it claims to be something more: a place for co-imagining alternative futures. To succeed, it will need to be bolder. Even though the Berlin landscape is dotted with monuments to failed ideologies, such as the Stasi Museum, history did not end when the wall fell. To imagine new futures, this museum must free itself from the conceptual frameworks of the past.

Stephen Cave is executive director of the Leverhulme Centre for the Future of Intelligence at the University of Cambridge, UK.

e-mail: sjc53@cam.ac.uk 